\title{
The effect of implant-abutment junction position on crestal bone loss: A systematic review and meta-analysis
}

\author{
Muhammad H. A. Saleh BDS, MS, PhD ${ }^{1}$ ｜ Andrea Ravidà DDS, MS1 \\ Fernando Suárez-López del Amo DDS, MS² | Guo-Hao Lin DDS, MS ${ }^{3}$ \\ Farah Asa'ad BDS, MS, PhD4 ～Hom-Lay Wang DDS, MS, PhD5
}

${ }^{1}$ Department of Periodontics and Oral Medicine, University of Michigan School of Dentistry, Ann Arbor, Michigan

${ }^{2}$ Department of Periodontics, University of Oklahoma, College of Dentistry, Norman, Oklahoma

${ }^{3}$ Department of Orofacial Sciences, University of California, San Francisco, California

${ }^{4}$ Department of Biomedical, Surgical \& Dental Sciences, University of Milan, Milan, Italy

${ }^{5}$ Department of Periodontics and Oral Medicine, University of Michigan School of Dentistry, Ann Arbor, Michigan

\section{Correspondence}

Hom-Lay Wang, Department of Periodontics and Oral Medicine, University of Michigan School of Dentistry, 1011 North University Avenue, Ann Arbor, Michigan 48109-1078, USA.

Email: homlay@umich.edu

Funding information

University of Michigan Periodontal

Graduate Student Research Fund

\begin{abstract}
Purpose: To investigate the effect of the apico-coronal implant position on early and late crestal bone loss (CBL), in bone and tissue level implants.

Materials and methods: Electronic and manual literature searches were conducted for controlled clinical trials reporting on CBL before and after functional loading of implants. Random effects meta-analyses were applied to analyze the weighted mean difference (WMD) and meta-regression was conducted to investigate any potential influences of select confounding factors.

Results: Fourteen articles were included in the systematic review and 12 were included in the quantitative synthesis. For bone level implants, WMD comparing early CBL in equi and subcrestal placement was $0.15 \mathrm{~mm}(P=.18)$. For analyses of late $\mathrm{CBL}$ in bone level implants, equi and subcrestal placement revealed a $0.03 \mathrm{~mm} W M D(P=.88)$. Where in supra and subcrestal placement, WMD was $0.04 \mathrm{~mm}(P=.86)$. The comparison presented considerable heterogeneity between these two arms, where the $P$ value for chi-square test presented as .006 . Finally, for $C B L$ between supra and equicrestal placement, WMD was $-0.64 \mathrm{~mm}(P<.0001)$, favoring the supracrestal group. For tissue level implants, WM of early and late $\mathrm{CBL}$ in implants placed equi-crestally was $0.68 \pm 0.12 \mathrm{~mm}$ and $0.69 \pm 0.54 \mathrm{~mm}$, respectively, where for implants placed sub-crestally, the WM of CBL was $1.72 \pm 0.15 \mathrm{~mm}$ and $2.26 \pm 0.63 \mathrm{~mm}$, respectively.
\end{abstract}

Conclusion: Within the limitations of this study, it is recommended to place tissue level implants equicrestally, and bone level implants subcrestally.

\section{KEYWORDS}

bone remodeling, clinical study, dental implant, review, systematic

\section{1 | INTRODUCTION}

The root causes of crestal bone loss (CBL) around dental implants is a topic that is often challenged, and although the literature is dwelled with articles debating the topic, a verdict is yet to be reached. ${ }^{1,2}$ This is particularly true since the exact reasons behind $\mathrm{CBL}$ and the determinant factors upon which its magnitude fluctuates is still uncertain. ${ }^{2-4}$ It is known beforehand that if CBL is controlled, good esthetic outcomes can be sustained, ${ }^{5}$ and the likelihood of metal showing can be decreased. ${ }^{6,7}$ Crestal bone stability is usually considered a sign of implant success, ${ }^{8}$ presence of $\mathrm{CBL}$ in early stages is considered an indication of further bone loss progression, ${ }^{9}$ and $\mathrm{CBL}$ is often considered the first step preceding periimplantitis. ${ }^{10}$ Previously, studies investigating CBL could not differentiate early bone loss following surgical implant placement from bone remodeling resulting from biologic width formation after implant exposure to the oral cavity, apart from a disease process leading to peri-implantitis. ${ }^{11,12}$ All stated forms of $C B L$ were regarded as a single entity, a part of the "physiologic/inevitable" CBL after implant placement. ${ }^{13}$ Such differentiation is indispensable, for if we wish to control the initial physiologic response exhibited in CBL, we must know what caused it first-hand. ${ }^{2}$ 
Considering the key importance of CBL to implant success, several preclinical and clinical studies have investigating a variety of confounding biologic, technical, or biomechanical factors that could contribute to this phenomenon. ${ }^{1}$ Once any confounding factor is identified, implant manufacturers rush to incorporate innovative implant features, and even surgical protocols, to accommodate the newly identified considerations. ${ }^{14}$ Contributing factors include surgical manipulation of implant site, ${ }^{15}$ establishment of biologic width, ${ }^{16}$ foreign body reaction to titanium, ${ }^{17}$ reduced thickness of buccal bone, ${ }^{18}$ and reduced thickness of soft tissue ${ }^{19,20}$ at implant site. Meanwhile, designs and surgical modifications suggested to overcome these shortcomings included: platform switching, ${ }^{21}$ increasing the soft tissue thickness at the implant site, ${ }^{22}$ using regular and reduced implant diameters, ${ }^{23}$ and changing the implant-abutment junction position to the alveolar bone crest. ${ }^{24}$

Specifically, the position of implant-abutment junction (IAJ) with regard to the crestal bone has been regularly surveyed, ${ }^{25}$ postulating the notion that once an ideal apico-coronal implant position is acquired, minimum CBL will occur and a perfect, harmonious emergence profile could exist. The main proposition is usually based on the detrimental effects microgap has on the adjacent crestal bone. ${ }^{26}$ By definition the microgap is located at the IAJ which, with exception of soft tissue level implants, is located at the same level as crestal bone. Observing the behavior of crestal bone adjacent to IAJ suggests that strong inflammatory stimuli originate at the implant-abutment interface, and that there is a causal relationship between the degree of inflammation and the magnitude of $\mathrm{CBL}^{27}$ Thus, according to this postulation, if the microgap was placed away from crestal bone, only minimal bone loss will occur. $^{28,29}$ Several authors recommended placing IAJ subcrestally to avert anticipated bone loss, thus maintaining maximum implant bone level, and subsequently maintaining the initial soft tissue levels. ${ }^{29,30}$ This opinion is now gaining more popularity; particularly after human histological evidence presented in some studies. ${ }^{31}$ This clearly contradicts the mainstream classic literature, ${ }^{32,33}$ and manufacturers' recommendations; where both advocate placing implants at the same level of crestal bone (equicrestally) is advocated. Nevertheless, other studies recommend placing IAJ above the level of crestal bone (supracrestally), leaving a portion of the implant's machined/rough surface exposed. ${ }^{28,34,35}$ This again was suggested to safeguard the supporting crestal bone from the detrimental effects of the microgap. ${ }^{36}$ As previously mentioned, the position of IAJ is a product of implant design, and therefore, we ought not to expect resemblance in neither the magnitude and timing of $\mathrm{CBL}^{37}$ nor the dimensions of biologic width to be the similar to bone level implants. ${ }^{38}$

In 2014, a systematic review investigating few animal and human studies, took into consideration the potential effect of implant-abutment configuration and the positioning of the microgap on CBL. Unfortunately, the results were inconclusive due to shortage of relevant studies. ${ }^{39}$ Since then, numerous studies were published, investigating the effect of different apico-coronal implant positions on CBL. Hence, the aim of the current study was to investigate the possible association between the apico-coronal position of IAJ and early and late $\mathrm{CBL}$, in different implant configurations.

\section{MATERIALS AND METHODS}

\section{1 | Objective of the review}

The objective of this review was to address the following focused questions:

1. Does the apico-coronal position of IAJ affect early and late CBL?

2. Since IAJ position changes with different implant configurations, will there be a difference in CBL between bone and tissue level implants?

The focused question was built to aid searching through the literature, the question was founded in the PICO format, ${ }^{40}$ where Population(P): participants with osseointegrated implants; Intervention(I): position of IAJ to crestal bone; Comparison(C): implants placed in a different position than the intervention, and Outcome(O): crestal bone loss.

\subsection{1 | Population}

The population of interest consisted of healthy people with missing teeth which were replaced by restored dental implants in healed alveolar ridges, and placed in completely or partially edentulous, mandibular, or maxillary dental/alveolar arches.

\subsection{2 | Intervention}

Implant placement at any apico-coronal (vertical) position to the crestal bone was considered our intervention. These include implants placed with the IAJ at the same level of the crest (Equicrestal), below the level of crestal bone (Subcrestal), and above the level of crestal bone (Supracrestal).

\subsection{3 | Comparison}

Only studies that reported results of a comparison (control) implants which were placed in a different apico-coronal position than the intervention were included in this review. These included randomized and nonrandomized controlled clinical trials.

\subsection{4 | Outcome}

The outcomes were development of $\mathrm{CBL}$ around dental implants, as assessed by radiographic follow up. In order to standardize the definition of CBL to eliminate possible bias arising from using different definitions, studies investigating $\mathrm{CBL}$ were segregated into an early, and late $\mathrm{CBL}$ groups. Early $\mathrm{CBL}$ was defined as bone loss occurring after implant placement but before its restoration. A follow up period for early bone loss was chosen to be a maximum of 6 months. Late bone loss was defined as bone remodeling occurring after implant restoration, a follow-up period for that was chosen to be at least 12 months.

\subsection{5 | Information sources for data extraction}

Electronic and manual literature searches were conducted independently by two authors (AR and FA) in multiple databases including MEDLINE (OVID), EMBASE (OVID), and Cochrane Central Register of Controlled Trials (Cochrane Library) for reports published up to April 2016 without any language restrictions. Moreover, the grey literature 
at the New York Academy of Medicine Grey Literature Report (http:// greylit.org) and the register of clinical studies hosted by the U.S. National Institutes of Health (www.clinicaltrials.gov) were searched to further identify potential candidates for inclusion. Additionally, a manual search of periodontics- and implantology-related journal issues was performed: Journal of Dental Research, Journal of periodontology, Journal of clinical periodontology, International Journal of Periodontics and Restorative Dentistry, Clinical Oral Implants Research, International Journal of Oral and Maxillofacial Implants, and Clinical Implant Dentistry and Related Research. Furthermore, reference lists/bibliographies of all candidate full-text articles were searched. Finally, three experts in the field were consulted whether any additional reports can be included to our final search results. Reports in languages other than English, Italian and Spanish were translated by a native speaker of the corresponding foreign language for inclusion/exclusion determination.

\section{Literature screening process}

For the PubMed library search strategy, a combination of (MeSH and EMTREE) keywords were used for PubMed library: \&((/(("dental implants"[MeSH Terms] OR ("dental"[All Fields] AND "implants"[All Fields]) OR "dental implants"[All Fields]) OR (("titanium"[MeSH Terms] OR "titanium"[All Fields]) AND ("dental implants"[MeSH Terms] OR ("dental"[All Fields] AND "implants"[All Fields]) OR "dental implants"[All Fields])) AND (implant-abutment[All Fields] AND connection[All Fields])) OR (machined[All Fields] AND collar[All Fields])) OR microgap [All Fields]) OR (implant[All Fields] AND abutment[All Fields] AND connection[All Fields])) OR (crestal[All Fields] AND ("bone and bone$s$ "[MeSH Terms] OR ("bone"[All Fields] AND "bones"[All Fields]) OR "bone and bones"[All Fields] OR "bone"[All Fields]) AND level[All Fields])) AND ("1990/01/01"[PDAT]: “2017/05/27"[PDAT]) AND "humans"[MeSH Terms]. For EMBASE the key words were 'dental'/exp OR dental AND ('implants'/exp OR implants) OR 'titanium'/exp OR titanium AND ('dental'/exp OR dental) AND ('implants'/exp OR implants) AND 'implant abutment' AND ('connection'/exp OR connection) OR machined AND ('collar'/exp OR collar) OR microgap OR 'implant'/exp OR implant AND abutment AND ('connection'/exp OR connection) OR crestal AND ('bone'/exp OR bone) AND level AND [1-1-1990]/sd NOT [27-5-2017]/sd AND [1990-2017]/py. The screening of these database was limited to "humans." Potential articles were examined by two reviewers (AR and FA) and inclusion was assessed after discussion. The level of agreement between both reviewers was determined by freemarginal kappa scores (Figure 1).

\section{Eligibility criteria}

During the first step of selection, studies were accounted eligible for inclusion in this systematic review if they met the following criteria: (1) original prospective controlled clinical trials, (2) human studies, (3) overall inclusion of $\geq 10$ implants in each group, (4) radiographic follow-up of a maximum of 6 months after implant placement for submerged non-loaded implants (early remodeling measurement), (5) radiographic follow-up of at least 12 month after abutment connection (delayed remodeling measurement), (6) bone-level and tissue-level implants, (7) all known languages, and (8) published in an international peer reviewed journal. At the second stage, the following exclusion criteria were employed: (1) in vitro studies, (2) immediately placed implants, (3) non-responding authors for missing data, (4) double published articles, (5) articles not mentioning bone remodeling as an outcome, (6) locally or systemically compromised sites and/or conditions, and (7) retrospective studies, non-controlled prospective studies.

Data extraction and analyses

First, studies were retained based on data from screening of the title and abstracts, later the final stage of screening involved full-text reading by two reviewers (MS and AR) using a predetermined data extraction form to confirm the eligibility of each study based on the inclusion and exclusion criteria. During each stage, any disagreement was resolved by discussion with a third reviewer (FS).

\section{Reporting format}

The PRISMA-P checklist (Supporting Information Checklist S1) was followed for protocol preparation of this systematic review. ${ }^{41}$ All review methods were established entirely prior to the conduct of the review. The 27-item Preferred Reporting Items for Systematic Reviews and Meta-Analyses (PRISMA) statement ${ }^{42}$ was used to describe and summarizing the results of search progression, the screening process based on the PRISMA guidelines can be seen in Figure 1. This study followed the Assessment of Multiple Systematic Reviews guidelines (AMSTAR) ${ }^{43}$ to achieve the standards of reporting systematic reviews. Since this systematic review included both randomized controlled trials (RCTs) and non-randomized studies of healthcare interventions (NRSI), the AMSTAR 2 tool was used for self-evaluation and supplementary guidance, ${ }^{44}$ where rating the overall confidence in the results of this review was high.

Quality assessment of selected studies

Quality assessment was based on the published full-text article and was performed independently by two investigators (MS and AR). Any disagreements were resolved by discussion with a third investigator (FS). The assessment was performed in three separate phases. During phase I, a quality assessment of included articles ${ }^{45,46}$ of all selected fulltext articles was performed according to the revised recommendations of the CONSORT statement for evaluation of randomized controlled trials (Schulz et al. 2010). A predefined scoring system was used for the quality assessment of finally selected clinical studies. ${ }^{47}$ Based on the CONSORT statement, a 25-point assessment examining: (1) Title and introduction; (2) Methods; (3) Results; (4) Discussion, and (5) Other information, was completed for all selected studies (Supporting Information Table S1). For phase II of the assessment, any supplemental materials associated with the publication were examined and disagreements at this point were resolved by discussion.

In phase III, an overall estimation of the plausible risk of bias (low, moderate, or high) was performed for the selected studies. A low risk of bias was estimated when all of the criteria were met. A moderate risk was considered when one or more criteria were partly met, while a high risk of bias was estimated when one or more criteria were not met (Cochrane Handbook for Systematic Reviews of Interventions, version 5.1.0., http://www.cochrane.org/resources/handbook). ${ }^{48}$ The 

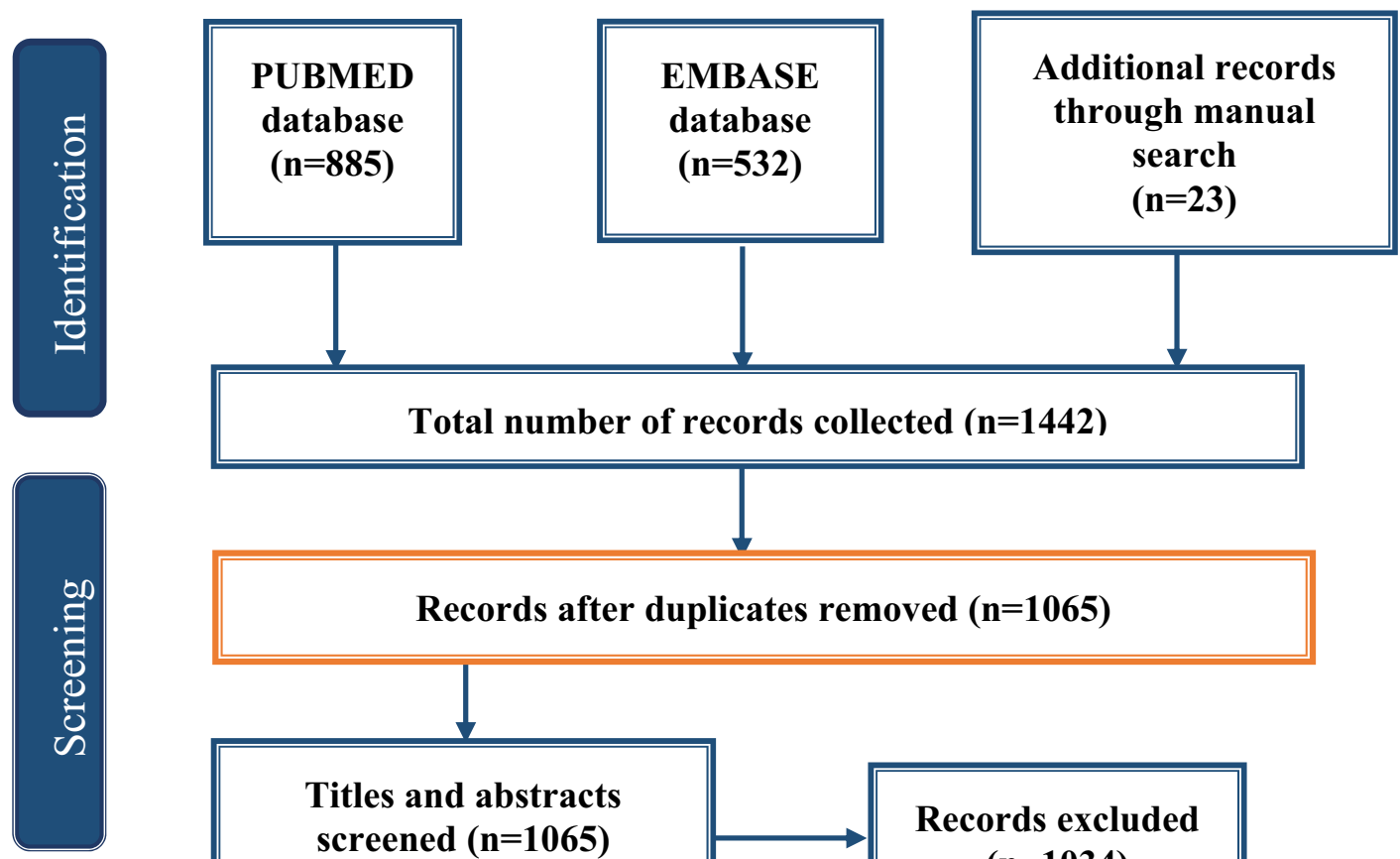

Total number of records collected $(n=1442)$
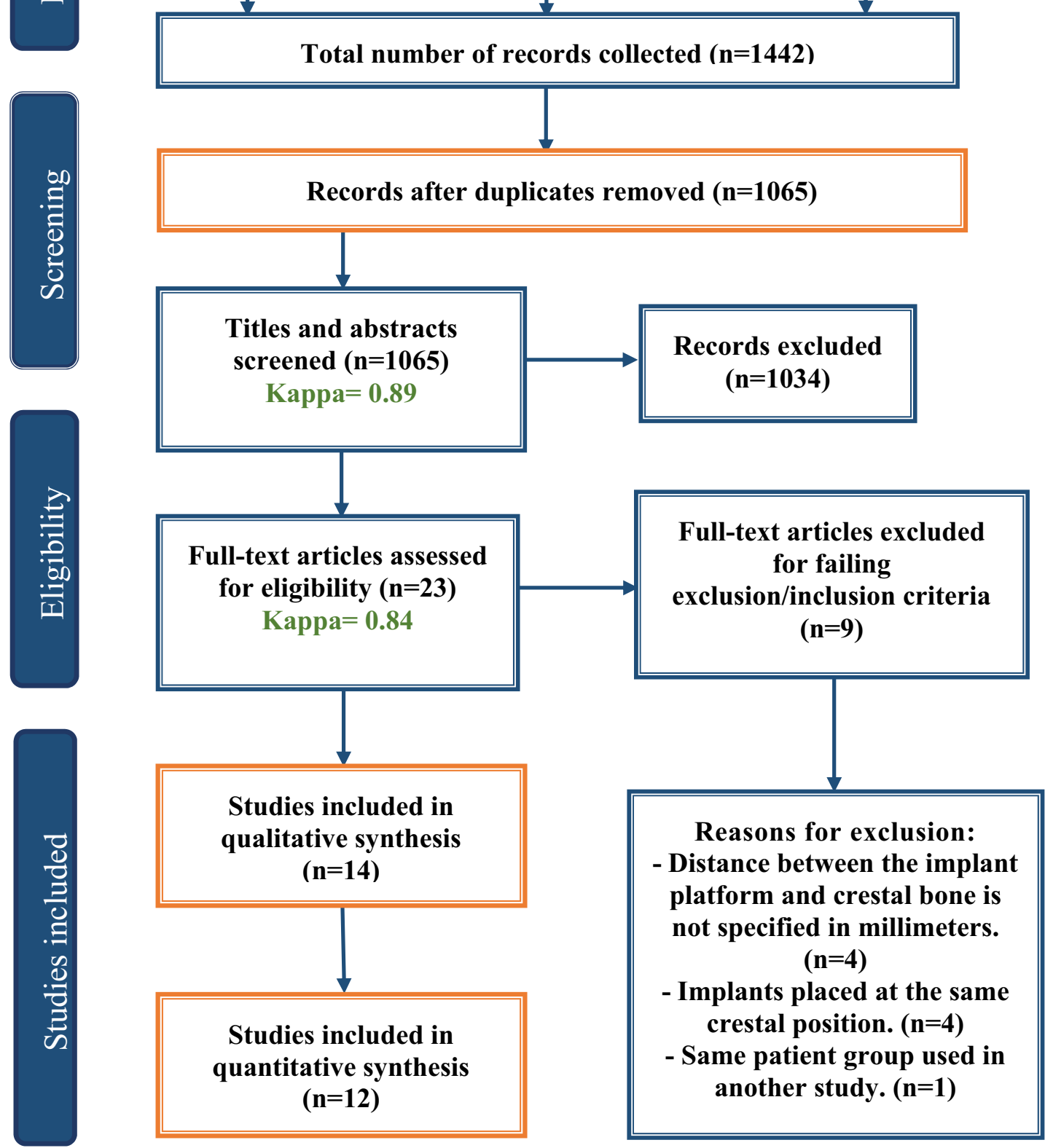

FIGURE 1 PRISMA flowchart of the screening process in the different databases

evaluated parameters included: (1) Random sequence, (2) Generation allocation concealment, (3) Blinding participants, (4) Blinding outcome assessment, (5) Incomplete outcome data addresses, (6) Selective outcome reporting, and (7) Other biases. The potential risk of bias was categorized as high if a study showed missing information of greater than two parameters, a moderate risk was considered if a study failed to provide information on only one of the parameters and low if a study provided detailed information about all the parameters (Figure 2).

\subsection{6 | Statistical analyses}

The primary outcome was the amount of CBL. The pooled weighted mean difference (WMD) of CBL between various implant placement protocols (supra-, sub-, and equi-crestal) at the timing of before and after abutment connection, were estimated using a computer program (RevMan Version 5.0. Copenhagen; The Nordic Cochrane Center, The Cochrane Collaboration, 2008). To avoid potential bias of combining the internal hex abutment and 


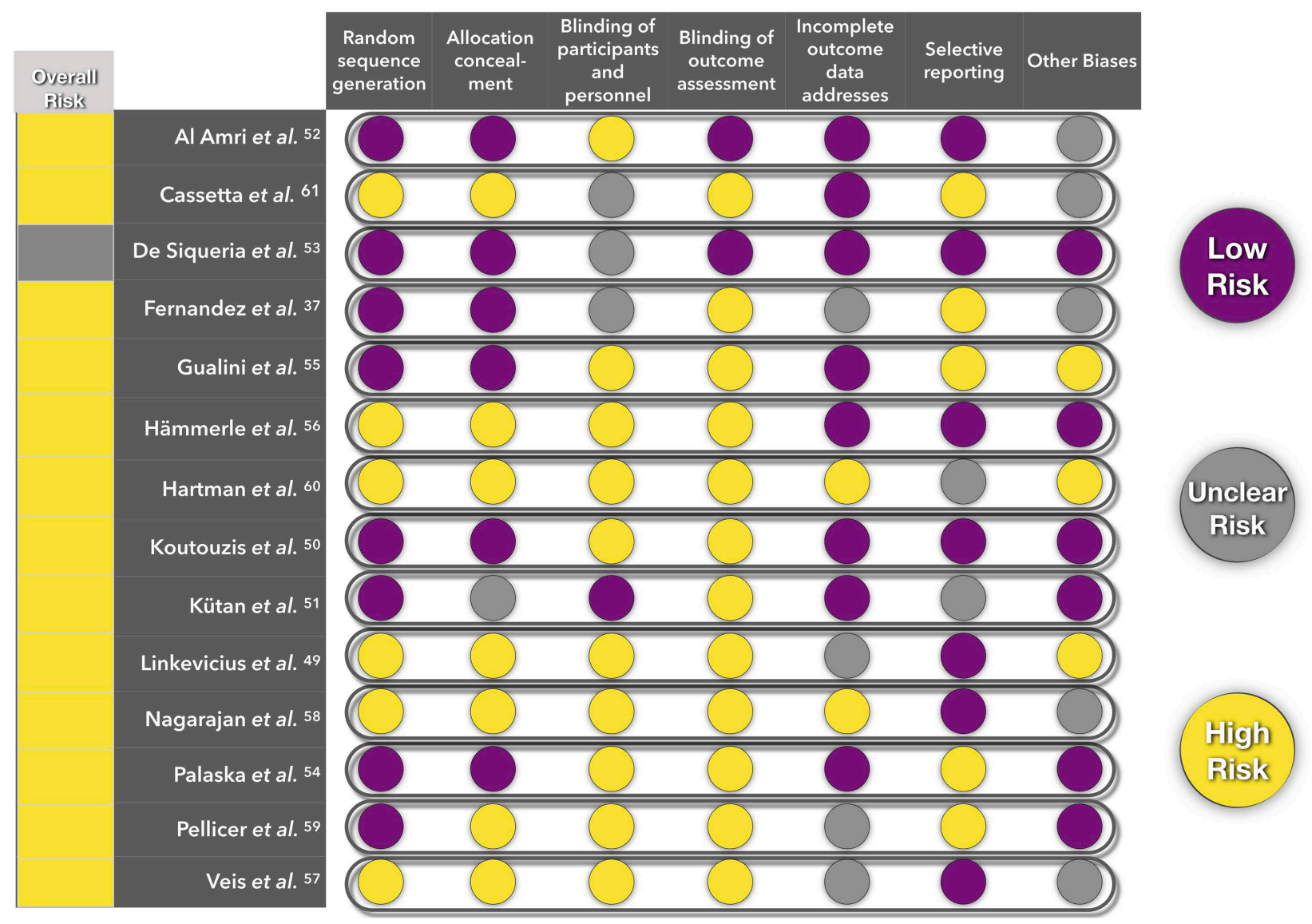

FIGURE 2 Risk of bias assessment

Morse taper connection, these abutment types were pooled separately as subgroup analyses. The contribution of each article was weighed. Random effects meta-analyses of the selected studies were performed to avoid any bias being caused by methodological differences between studies. Forest plots were produced to graphically represent the difference in outcomes of for all included studies using dental implant as the analysis unit. A $P$ val$\mathrm{ue}=.05$ was used as the level of significance. Heterogeneity was assessed with chi-square test and 12 test, which ranges between $0 \%$ and $100 \%$ and lower values representing less heterogeneity. In addition, the weighted mean (WM) and the standard deviation of $\mathrm{CBL}$ in each subgroup were also calculated using another computer program (Comprehensive Meta-Analysis Version 2, Biostat, Englewood, NJ).

\section{3 | RESULTS}

\section{1 | Study protocol}

The search and data extraction was done in adherence with the study protocol with no deviations. Search of titles, abstracts, and full-text articles, as well as the quality of selected studies were independently reviewed by two reviewers using a standard method to enable us from appraising our internal validity.

\section{2 | Study selection}

Initial screening yielded a total of 1,442 articles (885 PubMed, 532 EMBASE). Additionally, 23 more articles were found through manual screening. Overall, 1,065 potentially relevant articles were selected after an evaluation of their titles and abstracts, of which, 31 full texts of these articles were obtained and thoroughly evaluated. Of these, 14 articles fulfilled the inclusion criteria and were included in the qualitative synthesis. A total of 1,034 articles were excluded. Out of the 14 articles included in the systematic review, 12 were included in the quantitative synthesis and meta-analyzed to extract the influence of the variables on CBL. Figure 1 depicts the screening process based on the PRISMA guidelines and the Supporting Information Table S2 shows the exclusion justification for any study after full-text evaluation. The $k$ value for inter-reviewer agreement for potentially relevant articles was 0.87 (titles and abstracts) and 0.93 (full-text articles), indicating a consistent agreement between the two reviewers.

\section{3 | Characteristics of selected studies}

Eight articles were RCTs, ${ }^{37,49-55} 4$ were comparative controlled trials, ${ }^{56-59}$ and 2 were prospective cohorts. ${ }^{60,61}$ Of the 12 articles included in the meta-analysis, 3 measured early $\mathrm{CBL}$ in bone level implants, ${ }^{54,58,61} 7$ recorded late remodeling bone level implants, ${ }^{49-53,57,59}$ 
and 2 in tissue level implants. ${ }^{56,60}$ Details of all included studies are summarized in Tables 1 and 2.

\subsection{Findings based on our previous focused questions}

1. Is there an association between the apico-coronal position of IAJ with regard to early and late $\mathrm{CBL}$ ?

A. WMD of CBL between equicrestal and subcrestal placement before abutment connection

Three studies ${ }^{54,58,61}$ reported data on CBL of implants placed equicrestally and sub-crestally before abutment connection. One study ${ }^{61}$ used Morse taper cone connection abutment whereas another one ${ }^{58}$ used internal hex abutment. The third, ${ }^{54}$ used both configurations of implant-abutment connection. The WMD was $0.30 \mathrm{~mm}(95 \%$ $\mathrm{Cl}=-0.12$ to $0.72, P=.16)$ and $-0.11 \mathrm{~mm}(95 \% \mathrm{Cl}=-0.15$ to $-0.07, P<.0001$, favoring subcrestal placement) for Morse taper and internal hex subgroups, respectively (Figure 3 ). The overall analysis presented a WMD of $0.15 \mathrm{~mm}(95 \% \mathrm{Cl}=-0.07$ to $0.36, P=.18)$. However, the comparison presented a considerable heterogeneity among studies for Morse taper subgroup and the overall analysis; the $P$ value for chi-square test presented as $<.0001$ and $<.0001$, respectively. For internal hex subgroup, the $P$ value for chi-square test was .62, representing a low heterogeneity.

B. WMD of CBL between equicrestal and subcrestal placement after abutment connection

Six studies, ${ }^{50-53,57,59}$ reported data on CBL of implants placed equi-crestally and sub-crestally after abutment connection (mean 18.64 months). Five studies ${ }^{50-53,59}$ used Morse taper abutment and the remaining study ${ }^{57}$ used internal hex abutment. However, Veis et al. $(2010)^{57}$ introduced straight and platform switching abutment designs as study arms, therefore, these two arms were pooled separately. The WMD was $0.30 \mathrm{~mm}(95 \% \mathrm{Cl}=-0.15$ to $0.75, P=.19)$ and $-0.59 \mathrm{~mm}$ (95\% $\mathrm{Cl}=-0.90$ to $-0.28, P=.0002$, favoring subcrestal placement) for Morse taper and internal hex subgroups, respectively (Figure 4). The overall analysis presented a WMD of $0.03 \mathrm{~mm}(95 \% \mathrm{Cl}=-0.34$ to $0.40, P=.88$ ). However, the comparison presented a considerable heterogeneity among studies for Morse taper subgroup and the overall analysis; the $P$ value for chi-square test presented as $<.0001$ and $<.0001$, respectively. For internal hex subgroup, the $P$ value for chisquare test was 0.11 , representing a moderate heterogeneity.

C. WMD of CBL between supracrestal and subcrestal placement after abutment connection

One study ${ }^{57}$ reported data on CBL of supracrestal and subcrestal implants, using internal hex abutment after abutment connection. This study ${ }^{57}$ had straight and platform switching abutment designs as two separate study arms, therefore, these two arms were pooled. The WMD was $0.04 \mathrm{~mm}(95 \% \mathrm{Cl}=-0.46$ to $0.54, P=.86$, Figure 5$)$. The comparison presented a considerable heterogeneity between these two arms where the $P$ value for chi-square test presented as .006 .

D. WMD of CBL between supracrestal and equicrestal placement after abutment connection

Two studies ${ }^{49,57}$ reported data on CBL of supracrestal and equicrestal implants, using internal hex abutment after abutment connection. Again, since one study ${ }^{57}$ had straight and platform switching abutment designs as two separate study arms, therefore, these two arms were pooled separately. The WMD was $-0.64 \mathrm{~mm}(95 \%$ $\mathrm{Cl}=-0.92$ to $-0.35, P<.0001$, Figure 6 ), favoring supra-crestal group. The comparison presented a moderate heterogeneity among the studies where the $P$ value for chi-square test presented as .07 .

2. Is there a difference in CBL between bone and tissue level implants?

A. Tissue level implants

In terms of the studies using tissue level implants, none reported the $\mathrm{CBL}$ outcome when implants were placed supracrestally. For the implants placed equicrestally, the WM of CBL before and after abutment connection was $0.68 \pm 0.12 \mathrm{~mm}$ and $0.69 \pm 0.54 \mathrm{~mm}$, respectively. For the implants placed subcrestally, the WM of CBL before and after abutment connection was $1.72 \pm 0.15 \mathrm{~mm}$ and $2.26 \pm 0.63 \mathrm{~mm}$, respectively.

\section{B. WM of $C B L$ for each subgroup}

The WM of CBL for each subgroup is reported in Table 3. For the studies using bone level implants, the WM of CBL before and after abutment connection, when placed supracrestally, was $0.03 \pm 0.30 \mathrm{~mm}$ and $0.66 \pm 0.11 \mathrm{~mm}$, respectively. For the implants placed equicrestally, the WM of CBL before and after abutment connection was $0.57 \pm 0.29 \mathrm{~mm}$ and $0.80 \pm 0.30 \mathrm{~mm}$, respectively. For the implants placed subcrestally, the WM of CBL before and after abutment connection was $0.52 \pm 0.14 \mathrm{~mm}$ and $0.57 \pm 0.19 \mathrm{~mm}$, respectively. All results based on different configurations are shown in Table 3.

\section{5 | Quality assessment}

Only four studies ${ }^{52-55}$ reported their articles in concordance with the CONSORT statement. ${ }^{47}$ It is also worth mentioning that four studies were conducted before the CONSORT publication was available. Quality assessment of studies was performed as per the checklist item of (CONSORT) (Supporting Information Table S1). Majority of publications were particularly correlated with minimum scores when evaluating checklist items. When studies conducted before the CONSORT were compared to other studies, most compared items were not found to be equally adequate. Moreover, with risk of bias, they scored the highest (Figure 2).

\section{4 | DISCUSSION}

This review was designed to evaluate $C B L$ with the IAJ at different positions relative to the bone crest. Our investigation distinguished 


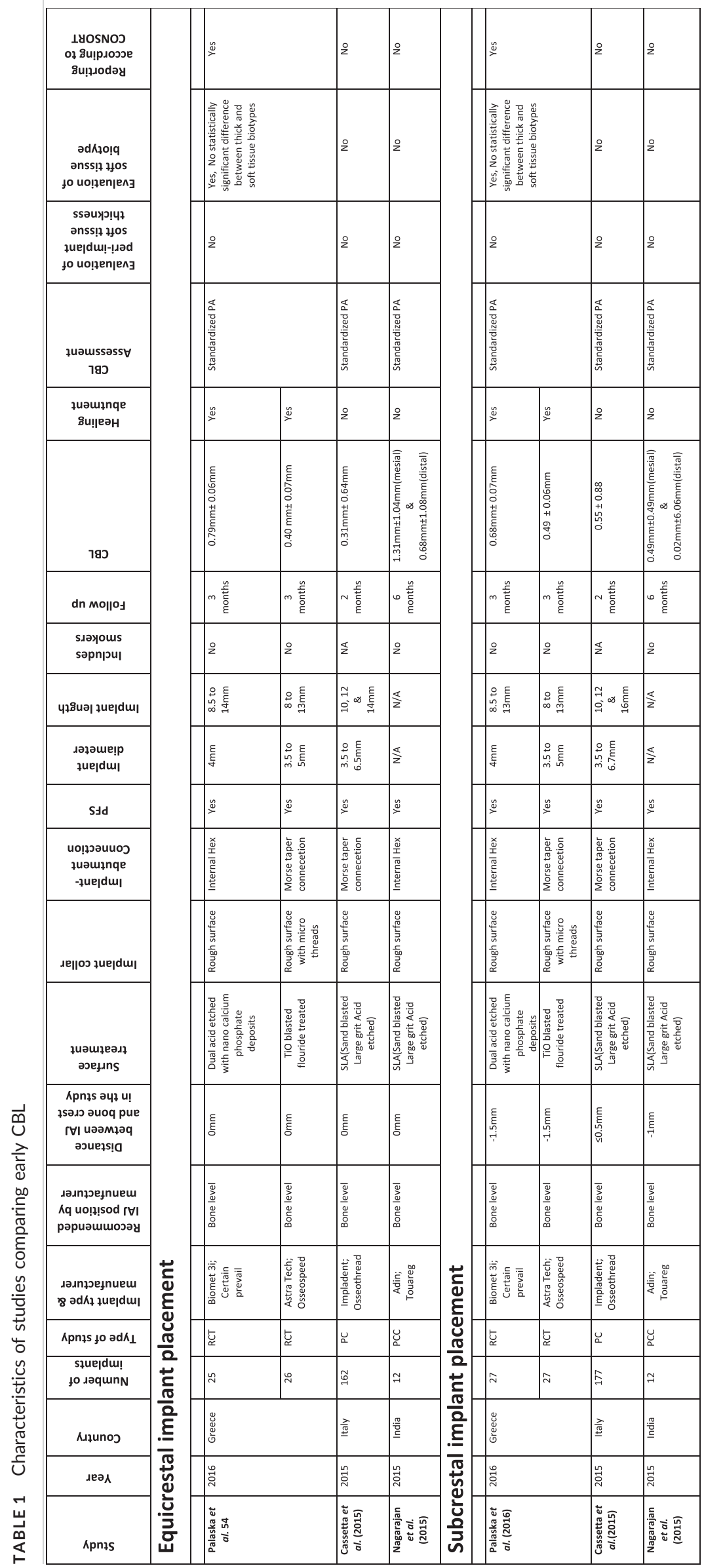




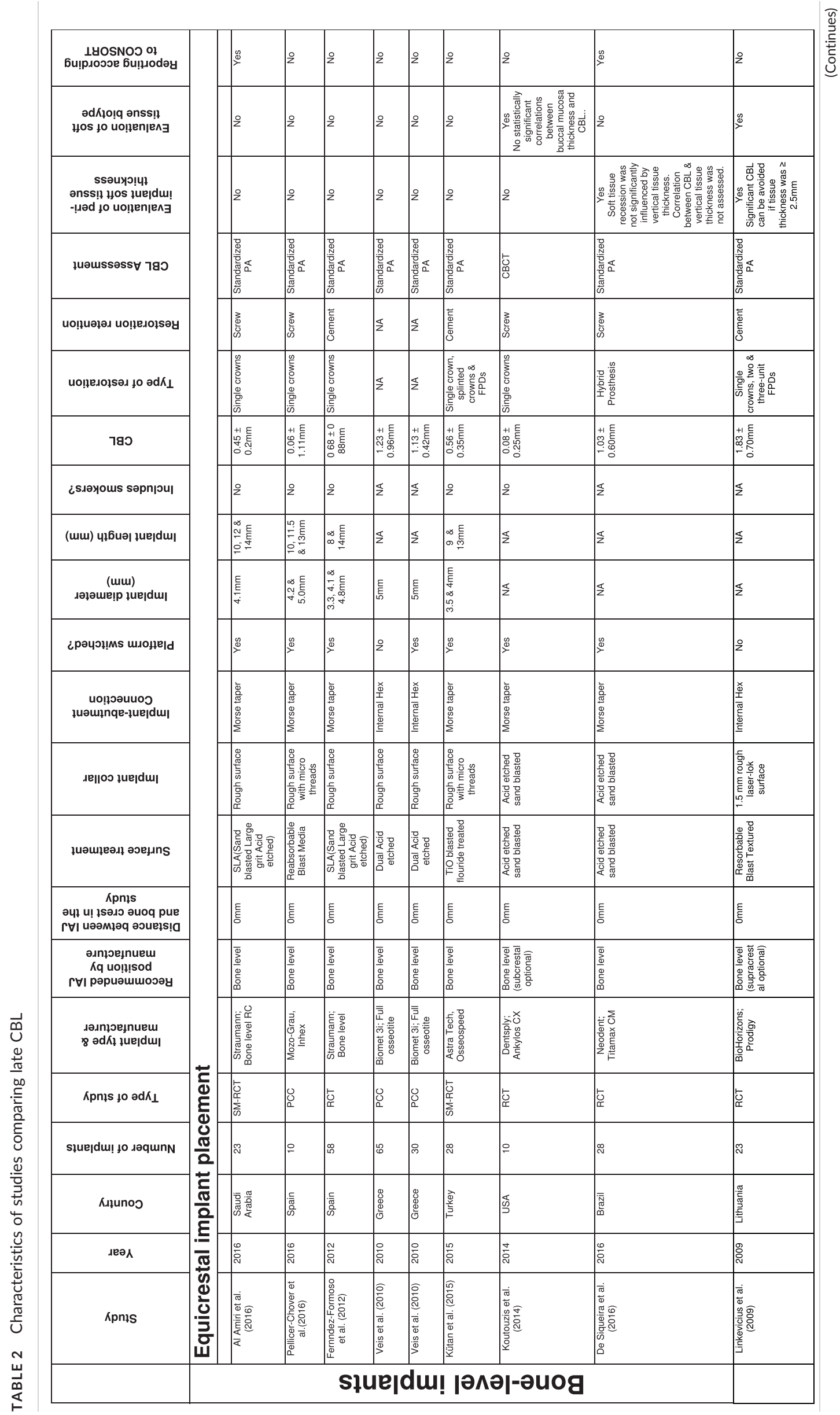




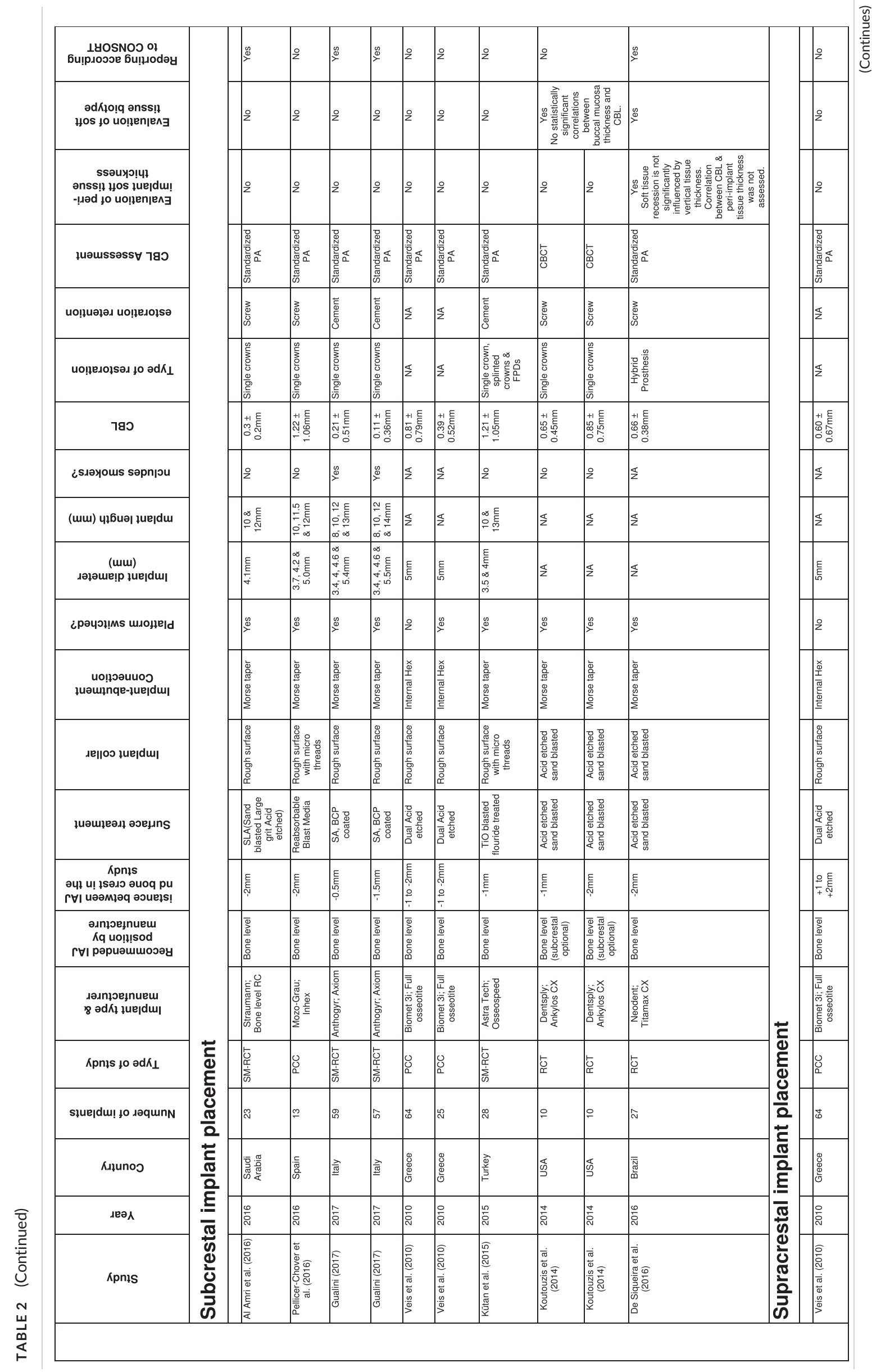




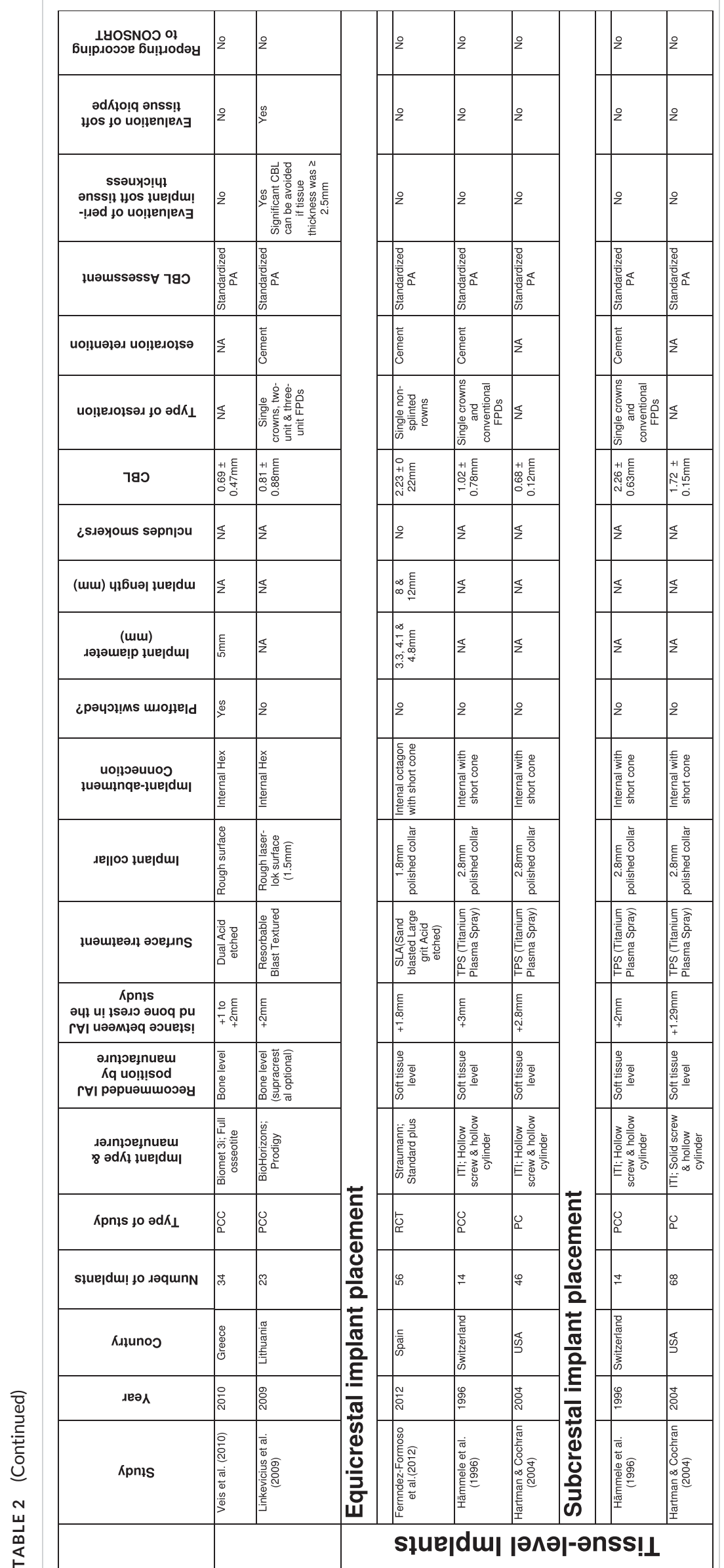




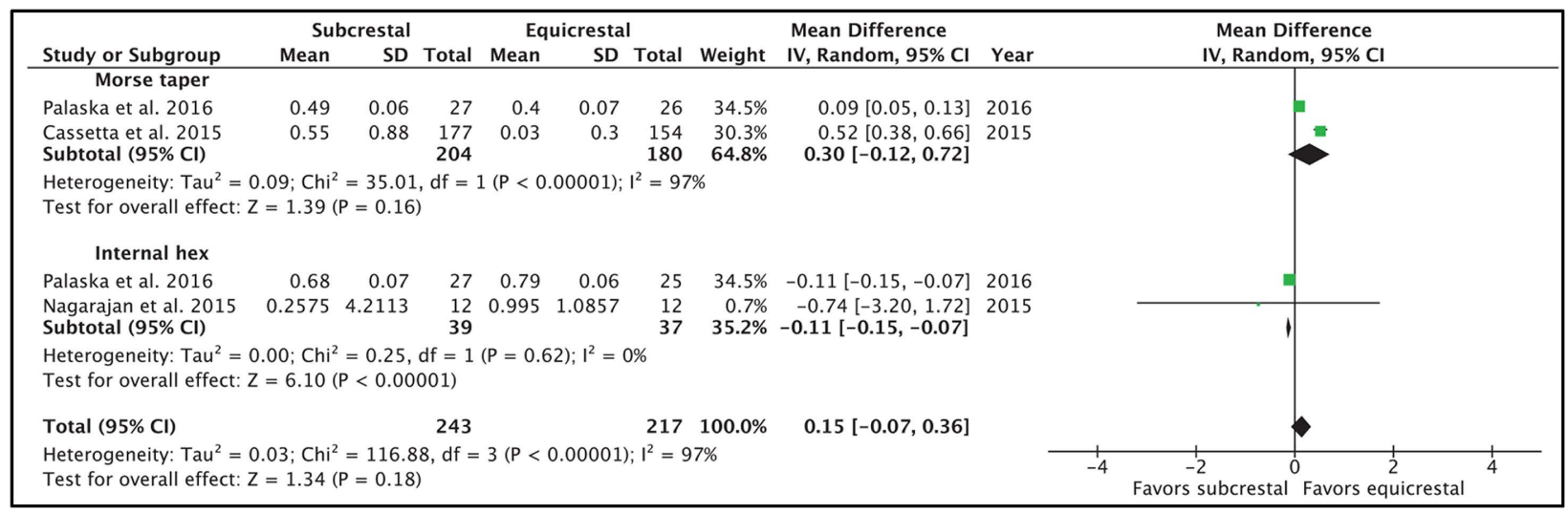

FIGURE 3 WMD of CBL between equicrestal and subcrestal placement before abutment connection

between two incidents of CBL. The first, occurring after surgical placement of an implant and before abutment connection. The second, which is after abutment connection and the succeeding functional loading. These two instances were segregated in an attempt to differentiate between an early bone loss that might occur postsurgery as a result of poor implant design, construction or placement by untrained clinicians, and a later bone loss that takes place due to bacterial leakage from the microgap, formation of biologic width, or overloading amongst other reasons. $^{62-64}$

For bone level implants, our results revealed that prior to abutment connection, a subcrestal IAJ position offers slightly less CBL than both a supracrestal and an equicrestal position, though, differences were not statistically significant. In contrast, after abutment connection, the least amount of CBL occurred when IAJ was placed supracrestally, and this result demonstrated otherwise to be statistically significant. Regarding tissue level implants, due to inherent implant design, the concept of different occurrences of remodeling based on abutment connection was not sensible. More late CBL was observed around implants were placed subcrestally versus equicrestally, where a statistical significance was found too. Contrarily, our results proposed that a subcrestal position leads to increased CBL than equicrestal position in tissue level implants.
Since the included studies comprised different implant designs, with varying configurations of implant-abutment connection, subsequent groups of results were pooled according to connection type. However, when doing so, all results were not found to be statistically significant.

When compared to bone level implants, tissue level implants have utterly different bounds. ${ }^{65}$ Tissue level implants are typically formed of a rough fixture surface and a relatively smooth collar, and behave biologically much similar to one-piece implants. In the original surgical protocol, it was recommended that the rough-to-smooth margin is placed at the level of the bone crest. ${ }^{66}$ This protocol presents an obvious biological advantage, but otherwise an esthetic detriment. The IAJ, and thus the microgap, are quite coronal from the crestal bone, which keeps crestal bone relatively protected. ${ }^{29}$ This position also results in a crown margin with an equigingival location, rendering in an easier hygiene control. On the other hand, the smooth collar is a compromise in esthetic zones; to keep it obscured subgingivally in preparation for unexpected facial bone loss, placing the rough-to-smooth border $1 \mathrm{~mm}$ subcrestally was suggested. ${ }^{6,67}$ In this case, a polished titanium surface that does not promote osseointegration will be in direct bone contact, resulting in a gradual resorption of adjacent bone. ${ }^{56,60}$

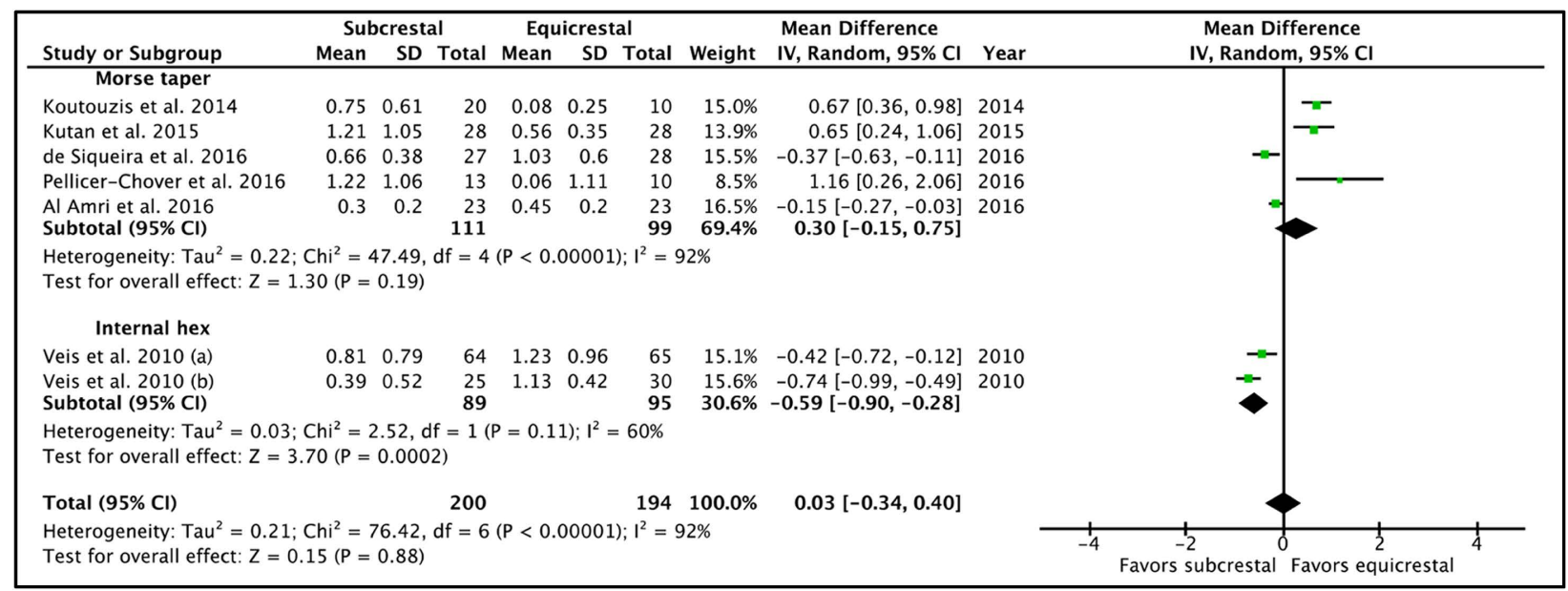

FIGURE 4 WMD of CBL between equicrestal and subcrestal placement after abutment connection 


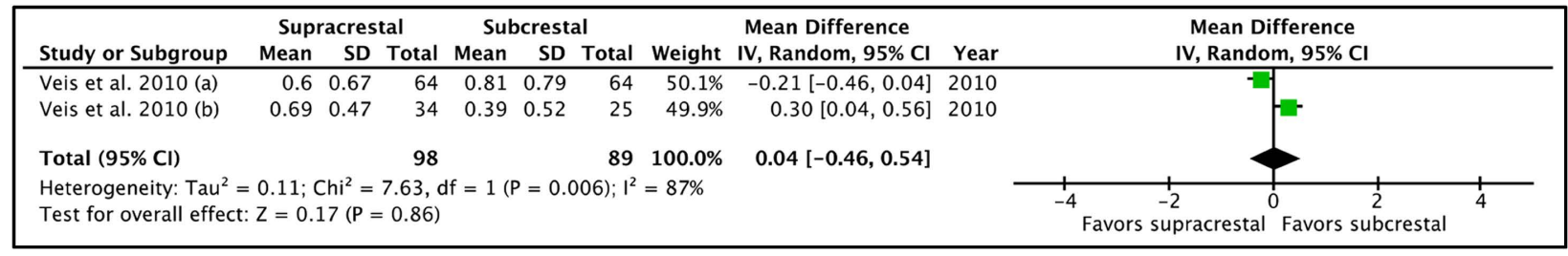

FIGURE 5 WMD of CBL between supracrestal and subcrestal placement after abutment connection in internal hex

\begin{tabular}{|c|c|c|c|c|c|c|c|c|c|c|}
\hline Study or Subgroup & \multicolumn{3}{|c|}{ Supracrestal } & \multicolumn{3}{|c|}{ Equicrestal } & Weight & $\begin{array}{l}\text { Mean Difference } \\
\text { IV, Random, } 95 \% \mathrm{CI}\end{array}$ & \multicolumn{2}{|c|}{$\begin{array}{c}\text { Mean Difference } \\
\text { IV, Random, } 95 \% \mathrm{CI}\end{array}$} \\
\hline Linkevicius et al. 2009 & 0.81 & 0.88 & 23 & 1.83 & 0.7 & 23 & $22.7 \%$ & $-1.02[-1.48,-0.56]$ & -1 & \\
\hline Veis et al. 2010 (a) & 0.6 & 0.67 & 64 & 1.23 & 0.96 & 65 & $35.6 \%$ & $-0.63[-0.92,-0.34]$ & - & \\
\hline Veis et al. $2010(b)$ & 0.69 & 0.47 & 34 & 1.13 & 0.42 & 30 & $41.8 \%$ & $-0.44[-0.66,-0.22]$ & $-ㄷ ㅡ$ & \\
\hline Total $(95 \% \mathrm{Cl})$ & & & 121 & & & 118 & $100.0 \%$ & $-0.64[-0.92,-0.35]$ & 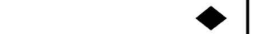 & \\
\hline \multicolumn{9}{|c|}{$\begin{array}{l}\text { Heterogeneity: } \mathrm{Tau}^{2}=0.04 ; \mathrm{Chi}^{2}=5.22, \mathrm{df}=2(P=0.07) ; \mathrm{I}^{2}=62 \% \\
\text { Test for overall effect: } Z=4.39(\mathrm{P}<0.0001)\end{array}$} & $\begin{array}{lcc}1 & 1 & 1 \\
-4 & -2 & 0 \\
& \text { Favors supracrestal }\end{array}$ & $\begin{array}{c}1 \\
2 \\
\text { Favors equicrestal }\end{array}$ \\
\hline
\end{tabular}

FIGURE 6 WMD of CBL between supracrestal and equicrestal placement after abutment connection in internal hex

Similarly, a subcrestal implant position was proposed in bone-level implants to improve esthetic results by yielding a sized running room for abutment and restoration. This, in turn, delivers an improved emergence profile and thus, an overall pleasing esthetic result. ${ }^{68}$ Vis-a-vis biologic consequences, if bone loss occurs, the exposed rough implant surface will facilitate plaque accumulation, and, therefore, possibly predispose to peri-implant disease. ${ }^{69}$ Though, at an early stage, judgment can be challenging, where no distinction exists between increased CBL and commencement of peri-implant disease except for more specific clinical signs. ${ }^{10}$

Since this is the first systematic review and meta-analysis discussing the topic through such approach, it is may be challenging to directly compare it with other studies; though some aspects of the study may still be compared with previous reviews. ${ }^{25,39}$ The first review examined late bone loss in specific situations for various implant configurations. Amongst the studies the first review examined, a total of 11 studies, among which only three are human, discussed the effect of IAJ position on CBL. The study results supported equicrestal placement of tissue level implants, where a subcrestal position was suggested for bone level implants. ${ }^{39}$ The second review discussed late bone loss in tissue versus bone level implants placed only in an equicrestal position. Four studies were selected for conducting the systematic review and meta-analysis. The study concluded that bone level implants suffered less late CBL than tissue level implants. ${ }^{25}$

One of the limitation of our results is that it does not apply to immediately placed implants. A CBCT study by Chappuis et al. ${ }^{70}$ reported that after tooth extraction, mean progressive bone resorption of facial bone was $48.3 \%$, versus merely $4.5 \%$ of interproximal alteration. This was later confirmed to result in more exaggerated facial bone loss in immediately placed implants. ${ }^{71}$ The stark conclusions made by studies similar to the latter ones led us to exclude all studies investigating $\mathrm{CBL}$ after immediate implant placement from our search.

Another major limitation of this study is its inability to detect the facial bone loss and its impact on esthetic outcome. Several studies directly correlated CBL with the projected facial bone loss and subsequently with any effects that might have on esthetics. It is well demonstrated that peri-implant dimensional alterations are most manifested in facial bone. An average of 0.7-1.3 mm reduction in buccal and lingual bone height, versus only $0.1 \mathrm{~mm}$ of proximal loss of bone height was reportedly observed. ${ }^{3}$ These findings could not have been just obtained via two dimensional periapical (PA) radiographs. It is thus a clear limitation of most studies included in this review, and almost all studies of similar nature, being dependent on PA radiographs as the select means of measuring CBL. Following the PA model leads to falling into two distinctive biases. The first is evidently that PA radiographs are incapable of measuring facial bone changes and thus their value is limited to interproximal crestal bone assessment. Second, knowing that the slightest vertical angulation might forfeit the reliability of CBL measurement, accuracy of measuring bone remodeling using PA's, though standardized, is questionable. ${ }^{72}$ This means that, if held reliable, PA radiographs should only be useful for assessing inter-proximal bone changes rather than circumferential $\mathrm{CBL}^{73}$ Given that, one would

TABLE 3 Results by main groups

\begin{tabular}{|lll|}
\hline & $\begin{array}{c}\text { Bone level } \\
\text { implants }(\mathrm{mm})\end{array}$ & $\begin{array}{l}\text { Tissue level } \\
\text { implants }(\mathrm{mm})\end{array}$ \\
\hline $\begin{array}{c}\text { Supracrestal before } \\
\text { abutment connection }\end{array}$ & $0.03 \pm 0.30$ & $\mathrm{~N} / \mathrm{A}$ \\
\hline $\begin{array}{c}\text { Supracrestal after } \\
\text { abutment connection }\end{array}$ & $0.66 \pm 0.11$ & $\mathrm{~N} / \mathrm{A}$ \\
\hline $\begin{array}{c}\text { Equicrestal before } \\
\text { abutment connection }\end{array}$ & $0.57 \pm 0.29$ & $0.68 \pm 0.12^{*}$ \\
\hline $\begin{array}{c}\text { Equicrestal after } \\
\text { abutment connection }\end{array}$ & $0.80 \pm 0.30$ & $0.69 \pm 0.54$ \\
\hline $\begin{array}{c}\text { Subcrestal before } \\
\text { abutment connection }\end{array}$ & $0.52 \pm 0.14$ & $1.72 \pm 0.15$ \\
\hline $\begin{array}{c}\text { Subcrestal after } \\
\text { abutment connection }\end{array}$ & $0.57 \pm 0.19$ & $2.26 \pm 0.63$ \\
\hline
\end{tabular}


assume using a $\mathrm{CBCT}$ to render the genuine $\mathrm{CBL}$, including the key facial bone loss. ${ }^{74}$ Yet inherent artifacts caused by titanium implants in $\mathrm{CBCT}$ scans decrease the visualization of bone-implant interface, making reliable assessment of facial and lingual bone inaccurate as well. $^{75,76}$

In the current investigation, a single study used CBCT for measuring $\mathrm{CBL}$, and was accordingly able to measure facial and lingual bone changes. ${ }^{50}$ Investigators in that study noticed that when implants were placed subcrestally, a $0 \%$ chance of crestal bone reaching a position apical to the IAJ existed; versus a 10\% chance when implants were placed equicrestally. This was consistently true for implants placed both at 1 and $2 \mathrm{~mm}$ subcrestally. Similar results were earlier reported in animal studies. ${ }^{77}$ If such an event occurs clinically in concordance with thin peri-implant soft tissue, exposure of the implant surface will be inevitable, eventually triggering It future biologic and esthetic concerns (Figure 7).

Soft tissue architecture facial to dental implants has been persistently used to evaluate the esthetic success of implant restorations, ${ }^{78,79}$

\section{Implant Placement}

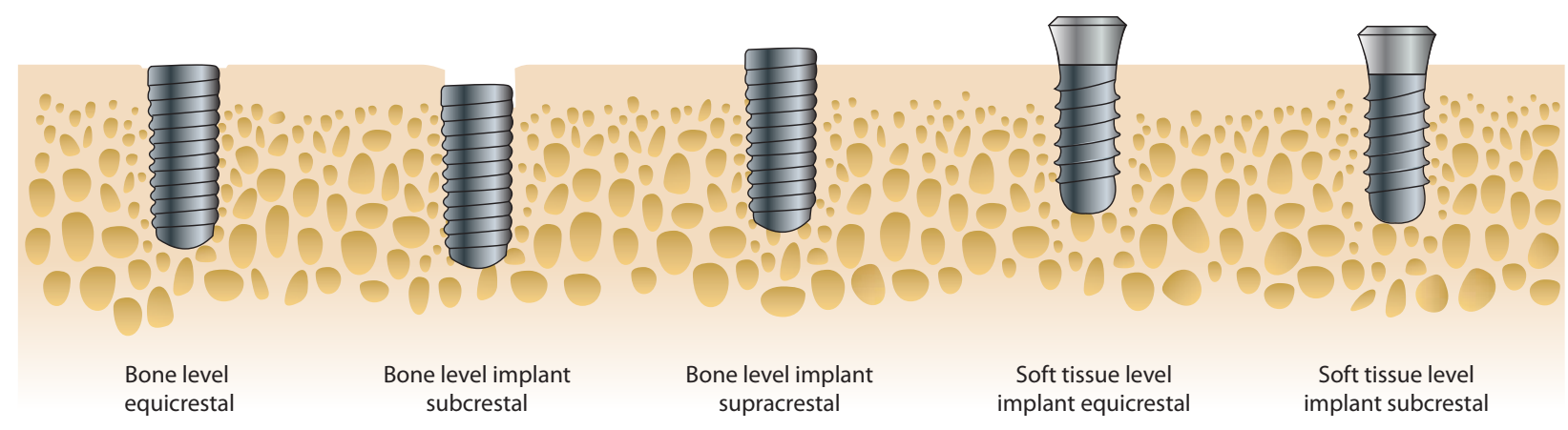

\section{Early Remodeling}

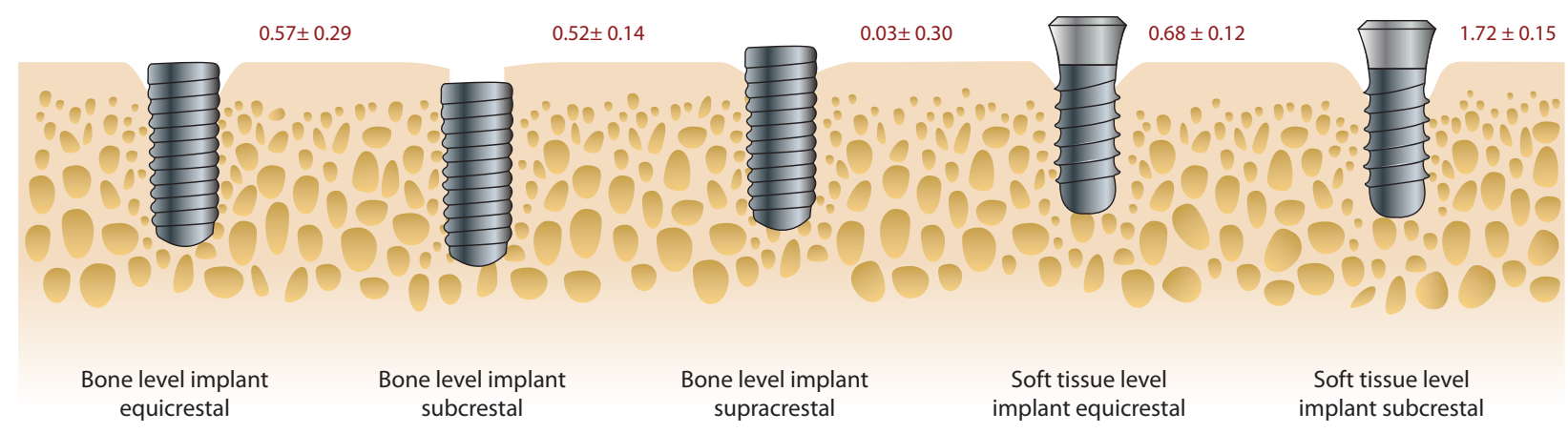

Late Remodeling

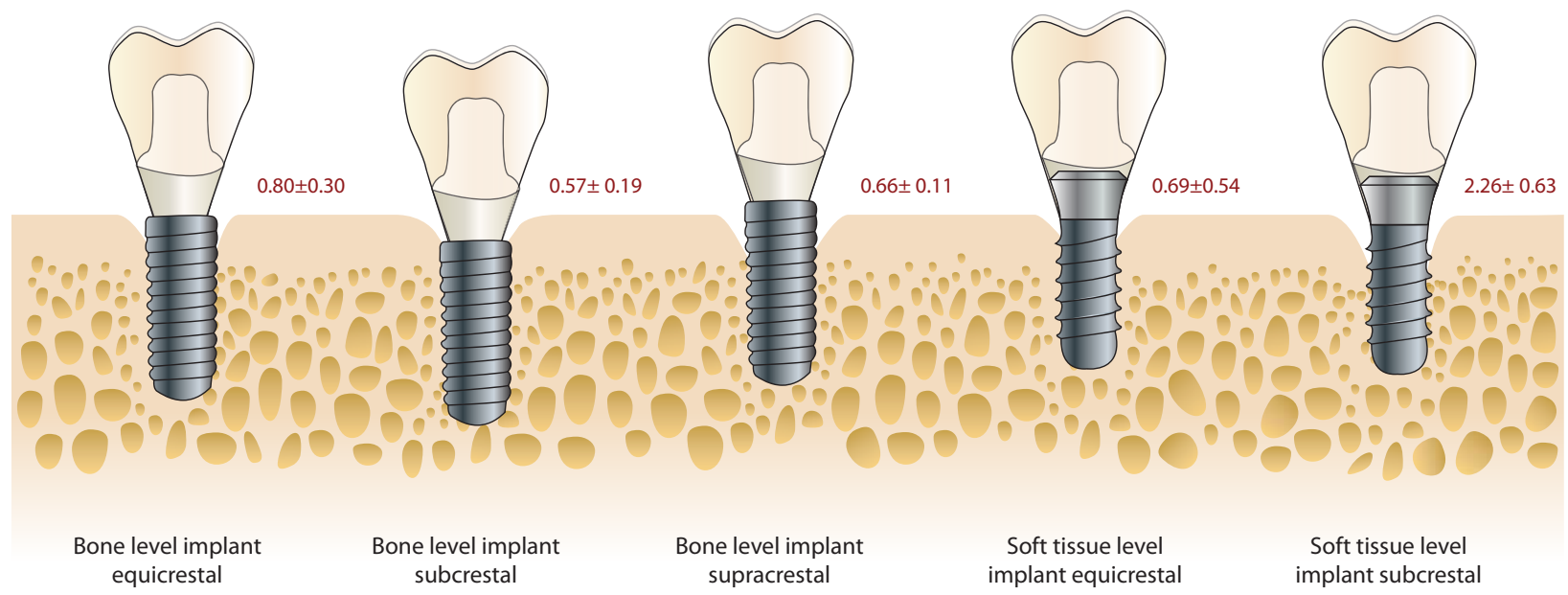

FIGURE 7 An illustration comparing CBL at implant placement, after early and late remodeling 
and was suggested to be determined by the underlying bony foundation. ${ }^{80}$ Similarly, oral soft tissue biotype and soft tissue thickness at implant site $20,81,82$ were shown to take part in etiology of CBL. A fact worth mentioning is that studies examining significance of soft tissue thickness in limiting CBL pointed out that placing implants supracrestaly will not satisfy the minimum dimension required for formation of biologic width, consequently defeating the purpose of a protective biologic zone, and leading to increased CBL. ${ }^{20}$ In the current review, only 1 study examined the effect of peri-implant tissue thickness on $\mathrm{CBL}$, and found that significant reduction in CBL occurred when tissue thickness was $>2 \mathrm{~mm}^{49}$

Though our results demonstrate statistically significant differences according to IAJ location, we doubt if it holds any considerable clinical significance. Rather, a slightly subcrestal implant position seems to keep implant platform covered with bone at all instances after the remodeling process occurs.

This study was focused on the timing and magnitude of CBL with a premise of IAJ being a key factor behind it. Regardless of IAJ position, differences in CBL remained quite within $1 \mathrm{~mm}$. As timidly revealed by this review, soft tissue thickness around implants, ${ }^{49}$ as well as the configuration of implant-abutment connection, ${ }^{54}$ might have a more profound effect on CBL than the IAJ position, and should therefore be investigated more meticulously through well designed, minimally-biased RCTs.

\section{5 | RECOMMENDATIONS FOR FUTURE STUDIES}

Although it might not be possible to blind the clinicians, blinding of the outcome assessors is suggested for any future research. Additionally, decreased heterogeneity and control of bias sources are strongly recommended. There is also an urgent need to find a more reliable, objective and reproducible method to measure facial bone changes around dental implants. Future studies might need to focus on the effect of implantabutment connection and soft tissue thickness around implants on CBL.

\section{6 | CONCLUSIONS}

With the aforementioned limitations and the high risk of bias found in the studies included in this review, the following conclusions can be cautiously drawn:

1. In bone level implants, the association between the apico-coronal position of the IAJ and CBL is statistically insignificant in all configurations except when supracrestal IA is compared to equicrestal. Rather, all results were found to be clinically insignificant.

2. There is a difference in the behavior of tissue level implants compared to bone level implants. Equicrestal placement of IA produces significantly less $\mathrm{CBL}$ than the subcrestal placement in tissue level implants.

3. Very limited evidence proposes that a subcrestal position of the IAJ might keep implant threads covered by bone after early and late $\mathrm{CBL}$ occurs.
4. Approximately $1 \mathrm{~mm}$ of $\mathrm{CBL}$ is expected after implant placement as a result of bone remodeling.

\section{CONFLICT OF INTEREST}

The authors declare that they have no conflicts of interest with the contents of this article. The authors do not have any financial interests, either directly or indirectly, in the products or information listed in the paper.

\section{ORCID}

Hom-Lay Wang DDS, MS, PhD (iD http://orcid.org/0000-0003-4238-1799

\section{REFERENCES}

[1] Schwarz F, Alcoforado G, Nelson K, et al. Impact of implantabutment connection, positioning of the machined collar/microgap, and platform switching on crestal bone level changes. Camlog Foundation Consensus Report. Clin Oral Implants Res. 2014;25(11):13011303.

[2] Albrektsson T, Chrcanovic B, Östman PO, Sennerby L. Initial and long-term crestal bone responses to modern dental implants. Periodontol 2000. 2017;73(1):41-50.

[3] Cardaropoli G, Lekholm U, Wennström JL. Tissue alterations at implant-supported single-tooth replacements: a 1-year prospective clinical study. Clin Oral Implants Res. 2006;17(2):165-171.

[4] De Bruyn H, Vandeweghe S, Ruyffelaert C, Cosyn J, Sennerby L. Radiographic evaluation of modern oral implants with emphasis on crestal bone level and relevance to peri-implant health. Periodontol 2000. 2013;62(1):256-270.

[5] Belser UC, Buser D, Hess D, Schmid B, Bernard JP, Lang NP. Aesthetic implant restorations in partially edentulous patients-a critical appraisal. Periodontol 2000. 1998;17(1):132-150.

[6] Buser D, Dula K, Belser U, Hirt HP, Berthold H. Localized ridge augmentation using guided bone regeneration. 1. Surgical procedure in the maxilla. Int J Periodont Restor Dent. 1993;13:29-45.

[7] Buser D, Arx T. Surgical procedures in partially edentulous patients with ITI implants. Clin Oral Implants Res. 2000;11:83-100.

[8] Albrektsson T, Zarb G, Worthington P, Eriksson AR. The long-term efficacy of currently used dental implants: a review and proposed criteria of success. Int J Oral Maxillofac Implants. 1986;1:11-25.

[9] Galindo-Moreno P, León-Cano A, Ortega-Oller I, Monje A, O’Valle F, Catena A. Marginal bone loss as success criterion in implant dentistry: beyond 2 mm. Clin Oral Implants Res. 2015;26(4):e28-e34.

[10] Fransson C, Wennström J, Berglundh T. Clinical characteristics at implants with a history of progressive bone loss. Clin Oral Implants Res. 2008;19(2):142-147.

[11] Albrektsson T, Brånemark P-I, Hansson H-A, Lindström J. Osseointegrated titanium implants.Requirements for ensuring a long lasting, direct bone-to-implant anchorage in man. Acta Orthop Scan. 1981; 52(2):155-170.

[12] Roos-Jansåker AM, Renvert H, Lindahl C, Renvert S. Nine- to fourteen-year follow-up of implant treatment. Part III: factors associated with peri-implant lesions. J Clin Periodontol. 2006;33(4):296301.

[13] Terheyden H, Lang NP, Bierbaum S, Stadlinger B. Osseointegration communication of cells. Clin Oral Implants Res. 2012;23(10):1127-1135.

[14] von Wilmowsky C, Moest T, Nkenke E, Stelzle F, Schlegel KA. Implants in bone: part I. A current overview about tissue response, 
surface modifications and future perspectives. Oral Maxillofac Surg. 2014;18(3):243-257.

[15] Naert I, Gizani S, van Steenberghe D, et al. Bone behavior around sleeping and non sleeping implants retaining a mandibular hinging overdenture. Clin Oral Implants Res. 1999;10(2):149-154.

[16] Berglundh T, Lindhe J, Ericsson I, Marinello CP, Liljenberg B, Thomsen P. The soft tissue barrier at implants and teeth. Clin Oral Implants Res. 1991;2(2):81-90.

[17] Albrektsson T, Dahlin C, Jemt T, Sennerby L, Turri A, Wennerberg A. Is marginal bone loss around oral implants the result of a provoked foreign body reaction?. Clin Implant Dent Relat Res. 2014;16 (2):155-165

[18] Spray JR, Black CG, Morris HF, Ochi S. The influence of bone thickness on facial marginal bone response: stage 1 placement through stage 2 uncovering. Ann Periodontol. 2000;5(1):119-128.

[19] Berglundh T, Lindhe J. Dimension of the periimplant mucosa biological width revisited short communication. J Clin Periodontol. 1996;23 (10):971-973.

[20] Linkevicius T, Puisys A, Steigmann M, Vindasiute E, Linkeviciene L. Influence of vertical soft tissue thickness on crestal bone changes around implants with platform switching: a comparative clinical study. Clin Implant Dent Relat Res. 2015;17(6):1228-1236.

[21] Atieh MA, Ibrahim HM, Atieh AH. Platform switching for marginal bone preservation around dental implants: a systematic review and meta-analysis. J Periodontol. 2010;81(10):1350-1366.

[22] Puisys A, Linkevicius T. The influence of mucosal tissue thickening on crestal bone stability around bone-level implants. A prospective controlled clinical trial. Clin Oral Implants Res. 2015;26(2):123-129.

[23] Petrie CS, Williams JL. Comparative evaluation of implant designs: influence of diameter, length, and taper on strains in the alveolar crest - A three-dimensional finite-element analysis. Clin Oral Implants Res. 2005;16(4):486-494.

[24] Jung YC, Han CH, Lee KW. A 1-year radiographic evaluation of marginal bone around dental implants. Int J Oral Maxillofac Implant. 1996;11:811-818.

[25] van Eekeren P, Tahmaseb A, Wismeijer D. Crestal bone changes around implants with implant-abutment connections at epicrestal level or above: systematic review and meta-analysis. Int J Oral Maxillofac Implants. 2016;31:119-124.

[26] Quirynen M, van Steenberghe D. Bacterial colonization of the internal part of two-stage implants: an in vivo study. Clin Oral Implants Res. 1993;4(3):158-161.

[27] Broggini N, McManus LM, Hermann JS, et al. Persistent acute inflammation at the implant-abutment interface. J Dent Res. 2003; 82(3):232-237.

[28] Piattelli A, Vrespa G, Petrone G, lezzi G, Annibali S, Scarano A. Role of the microgap between implant and abutment: a retrospective histologic evaluation in monkeys. J Periodontol. 2003;74(3):346-352.

[29] Broggini N, McManus LM, Hermann JS, et al. Peri-implant inflammation defined by the implant-abutment interface. J Dent Res. 2006;85(5):473-478.

[30] Barros RRM, Novaes AB, Muglia VA, lezzi G, Piattelli A. Influence of interimplant distances and placement depth on peri-implant bone remodeling of adjacent and immediately loaded Morse cone connection implants: a histomorphometric study in dogs. Clin Oral Implants Res. 2010;21(4):371-378.

[31] Degidi M, Perrotti V, Shibli JA, Novaes AB, Piattelli A, lezzi G Equicrestal and subcrestal dental implants: a histologic and histomorphometric evaluation of nine retrieved human implants. J Periodontol. 2011;82(5):708-715.
[32] Adell R, Lekholm U, Rockler B, Brånemark PI. A 15-year study of osseointegrated implants in the treatment of the edentulous jaw. Int J Oral Surg. 1981;10(6):387-416.

[33] Albrektsson T, Jansson T, Lekholm U. Osseointegrated dental implants. Dent Clin North Am. 1986;30:151-174.

[34] Todescan FF, Pustiglioni FE, Imbronito AV, Albrektsson T, Gioso M. Influence of the microgap in the peri-implant hard and soft tissues: a histomorphometric study in dogs. Int J Oral Maxillofac Implants. 2002;17(4):467-472.

[35] Nevins M, Nevins ML, Camelo M, Boyesen JL, Kim DM. Human histologic evidence of a connective tissue attachment to a dental implant. Int J Periodont Restor Dent. 2008;28:111-121.

[36] Al-Nawas B, Kämmerer PW, Morbach T, Ladwein C, Wegener J, Wagner W. Ten-year retrospective follow-up study of the TiOblast ${ }^{\mathrm{TM}}$ dental implant. Clin Implant Dent Relat Res. 2012;14(1):127-134.

[37] Fernández-Formoso N, Rilo B, Mora MJ, Martínez-Silva I, DíazAfonso AM. Radiographic evaluation of marginal bone maintenance around tissue level implant and bone level implant: a randomised controlled trial. A 1-year follow-up. J Oral Rehabil. 2012;39(11): 830-837.

[38] Hermann JS, Buser D, Schenk RK, Schoolfield JD, Cochran DL. Biologic Width around one- and two-piece titanium implants. Clin Oral Implants Res. 2001;12:559-571.

[39] Schwarz F, Hegewald A, Becker J. Impact of implant-abutment connection and positioning of the machined collar/microgap on crestal bone level changes: a systematic review. Clin Oral Implants Res. 2014;25(4):417-425.

[40] Stone PW. Popping the (PICO) question in research and evidencebased practice. Appl Nurs Res. 2002;15(3):197-198.

[41] Shamseer L, Moher D, Clarke M, PRISMA-P Group, et al. Preferred reporting items for systematic review and meta-analysis protocols (PRISMA-P) 2015: elaboration and explanation. BMJ. 2015;4(1); g7647.

[42] Moher D, Liberati A, Tetzlaff J, Altman DG, PRISMA Group. Preferred reporting items for systematic reviews and meta-analyses: the PRISMA statement. Ann Intern Med. 2009;151:264-269.

[43] Shea BJ, Hamel C, Wells GA, et al. AMSTAR is a reliable and valid measurement tool to assess the methodological quality of systematic reviews. J Clin Epidemiol. 2009;62(10):1013-1020.

[44] Shea BJ, Reeves BC, Wells G, et al. AMSTAR 2: a critical appraisal tool for systematic reviews that include randomised or nonrandomised studies of healthcare interventions, or both. Bmj. 2017; 358:j4008.

[45] Berglundh T, Stavropoulos A. Preclinical in vivo research in implant dentistry. Consensus of the eighth European workshop on periodontology. J Clin Periodontol. 2012;39:1-5.

[46] Tonetti M, Palmer R. Clinical research in implant dentistry: study design, reporting and outcome measurements: consensus report of Working Group 2 of the VIII European Workshop on Periodontology. J Clin Periodontol. 2012;39:73-80.

[47] Schulz KF, Altman DG, Moher D, CONSORT Group. CONSORT 2010 statement: updated guidelines for reporting parallel group randomised trials. Bmj. 2010;340:c332.

[48] Higgins JPT, Altman DG, Gotzsche PC, et al. The Cochrane Collaboration's tool for assessing risk of bias in randomised trials. Bmj. 2011;343(2):d5928.

[49] Linkevicius T, Apse P, Grybauskas S, Puisys A. The influence of soft tissue thickness on crestal bone changes around implants: a 1-year prospective controlled clinical trial. Int J Oral Maxillofac Implants. 2009;24:712-719. 
[50] Koutouzis T, Neiva R, Nair M, Nonhoff J, Lundgren T. Cone beam computed tomographic evaluation of implants with platformswitched morse taper connection with the implant-abutment interface at different levels in relation to the alveolar crest. Int J Oral Maxillofac Implants. 2014;29(5):1157-1163.

[51] Kütan E, Bolukbasi N, Yildirim-Ondur E, Ozdemir T. Clinical and radiographic evaluation of marginal bone changes around platformswitching implants placed in crestal or subcrestal positions: a randomized controlled clinical trial. Clin Implant Dent Relat Res. 2015;17 Suppl 2:e364-e375.

[52] Al Amri MD, Al-Johany SS, Al Baker AM, Al Rifaiy MQ, Abduljabbar TS, Al-Kheraif AA. Soft tissue changes and crestal bone loss around platform-switched implants placed at crestal and subcrestal levels: 36-month results from a prospective split-mouth clinical trial. Clin Oral Implants Res. 2016;28:1342-1347.

[53] de Siqueira RAC, Fontão FNGK, Sartori IA, de M, et al. Effect of different implant placement depths on crestal bone levels and soft tissue behavior: a randomized clinical trial. Clin Oral Implants Res. 2016;28:1227-1233.

[54] Palaska I, Tsaousoglou P, Vouros I, Konstantinidis A, Menexes G. Influence of placement depth and abutment connection pattern on bone remodeling around 1-stage implants: a prospective randomized controlled clinical trial. Clin Oral Implants Res. 2016;27(2):e47-e56.

[55] Gualini F, Salina S, Rigotti F, Mazzarini C, Longhin D, Grigoletto M. Subcrestal placement of dental implants with an internal conical connection of $0.5 \mathrm{~mm}$ versus $1.5 \mathrm{~mm}$ : outcome of a multicentre randomised controlled trial 1 year after loading. Eur J Oral Implantol. 2017;10:73-82.

[56] Hämmerle CHF, Brägger U, Bürgin W, Lang NP. The effect of subcrestal placement of the polished surface of ITI $\circledast$ implants on marginal soft and hard tissues. Clin Oral Implants Res. 1996;7(2):111-119.

[57] Veis A, Parissis N, Tsirlis A, Papadeli C, Marinis G, Zogakis A. Evaluation of peri-implant marginal bone loss using modified abutment connections at various crestal level placements. Int J Periodont Restor Dent. 2010;30:609-617.

[58] Nagarajan B, Murthy V, Livingstone D, Surendra MP, Jayaraman S. Evaluation of crestal bone loss around implants placed at equicrestal and subcrestal levels before loading: a prospective clinical study. J Clin Diagn Res. 2015;9:47-50.

[59] Pellicer-Chover H, Peñarrocha-Diago $M$, Peñarrocha-Oltra $D$, Gomar-Vercher S, Agustín-Panadero R, Peñarrocha-Diago M. Impact of crestal and subcrestal implant placement in peri-implant bone: a prospective comparative study. Med Oral Patol Oral Cir Bucal. 2016; 21:e103-e110.

[60] Hartman GA, Cochran DL. Initial implant position determines the magnitude of crestal bone remodeling. J Periodontol. 2004 Apr;75 (4):572-577.

[61] Cassetta M, Pranno N, Calasso S, Di Mambro A, Giansanti M. Early peri-implant bone loss: a prospective cohort study. Int J Oral Maxillofac Surg. 2015;44(9):1138-1145.

[62] Hermann JS, Buser D, Schenk RK, Cochran DL. Crestal bone changes around titanium implants. A histometric evaluation of unloaded non-submerged and submerged implants in the canine mandible. J Periodontol. 2000;71(9):1412-1424.

[63] Canullo L, Fedele GR, lannello G, Jepsen S. Platform switching and marginal bone-level alterations: the results of a randomizedcontrolled trial. Clin Oral Implants Res. 2010;21(1):115-121.

[64] Qian J, Wennerberg A, Albrektsson T. Reasons for marginal bone loss around oral implants. Clin Implant Dent Relat Res. 2012;14(6): 792-807.
[65] Hänggi MP, Hänggi DC, Schoolfield JD, Meyer J, Cochran DL, Hermann JS. Crestal bone changes around titanium implants. Part I: a retrospective radiographic evaluation in humans comparing two non-submerged implant designs with different machined collar lengths. J Periodontol. 2005;76(5):791-802.

[66] Sutter F, Schroeder A, Buser DA. The new concept of ITI hollowcylinder and hollow-screw implants: part 1. Engineering and design. Int J Oral Maxillofac Implants. 1988;3:161-172.

[67] Hess D, Buser D, Dietschi D, Grossen G, Schönenberger A, Belzer UC. Esthetic single-tooth replacement with implants: a team approach. Quintessence Int. 1998;29(2):77-86.

[68] Su H, Gonzalez-Martin O, Weisgold A, Lee E. Considerations of implant abutment and crown contour: critical contour and subcritical contour. Int J Periodont Restor Dent. 2010;30:335-343.

[69] Doornewaard R, Christiaens V, De Bruyn H, et al. Long-term effect of surface roughness and patients' factors on crestal bone loss at dental implants. A systematic review and meta-analysis. Clin Implant Dent Relat Res. 2017;19(2):372-399.

[70] Chappuis V, Engel O, Reyes M, Shahim K, Nolte L-P, Buser D. Ridge alterations post-extraction in the esthetic zone. J Dent Res. 2013;92 (12 Suppl):195S-201S.

[71] Kuchler U, Chappuis V, Gruber R, Lang NP, Salvi GE. Immediate implant placement with simultaneous guided bone regeneration in the esthetic zone: 10-year clinical and radiographic outcomes. Clin Oral Implants Res. 2016;27(2):253-257.

[72] Kühl S, Zürcher S, Zitzmann NU, Filippi A, Payer M, DagassanBerndt D. Detection of peri-implant bone defects with different radiographic techniques - a human cadaver study. Clin Oral Implants Res. 2016;27(5):529-534.

[73] Bornstein MM, Al-Nawas B, Kuchler U, Tahmaseb A. Consensus statements and recommended clinical procedures regarding contemporarysurgical and radiographic techniques in implant dentistry. Int $J$ Oral Maxillofac Implants. 2014;29(Suppl):78-82.

[74] Naitoh M, Nabeshima H, Hayashi H, Nakayama T, Kurita K, Ariji E. Postoperative assessment of incisor dental implants using conebeam computed tomography. J Oral Implantol. 2010;36(5):377-384.

[75] Bornstein MM, Horner K, Jacobs R. Use of cone beam computed tomography in implant dentistry: current concepts, indications and limitations for clinical practice and research. Periodontol 2000. 2017; 73(1):51-72.

[76] Rios HF, Borgnakke WS, Benavides E. The use of cone-beam computed tomography in management of patients requiring dental implants: an American Academy of Periodontology best evidence review. J Periodontol. 2017;88(10):946-959.

[77] Barros RR, Degidi M, Novaes AB, Piattelli A, Shibli JA, lezzi G. Osteocyte density in the peri-implant bone of immediately loaded and submerged dental implants. J Periodontol. 2009 Mar;80(3):499-504.

[78] Fürhauser R, Florescu D, Benesch T, Haas R, Mailath G, Watzek G. Evaluation of soft tissue around single-tooth implant crowns: the pink esthetic score. Clin Oral Implants Res. 2005;16(6):639-644.

[79] Benic GI, Mokti M, Chen CJ, Weber HP, Hämmerle CHF, Gallucci GO. Dimensions of buccal bone and mucosa at immediately placed implants after 7 years: a clinical and cone beam computed tomography study. Clin Oral Implants Res. 2012;23(5):560-566.

[80] Nisapakultorn K, Suphanantachat S, Silkosessak O, Rattanamongkolgul S. Factors affecting soft tissue level around anterior maxillary single-tooth implants. Clin Oral Implants Res. 2010;21(6):662-670.

[81] Suárez-López Del Amo F, Lin G, Monje A, Galindo-Moreno P, Wang $\mathrm{H}$. Influence of soft tissue thickness on peri-implant marginal bone 
loss: a systematic review and meta-analysis. J Periodontol. 2016;87 (6):690-699.

[82] Akcalı A, Trullenque-Eriksson A, Sun C, Petrie A, Nibali L, Donos N. What is the effect of soft tissue thickness on crestal bone loss around dental implants? A systematic review. Clin Oral Implants Res. 2017;28(9):1046-1053.

\section{SUPPORTING INFORMATION}

Additional Supporting Information may be found online in the supporting information tab for this article.

TABLE S1 Quality assessment of included studies according to the CONSORT statement
TABLE S2 Characteristics of excluded studies

CHECKLIST S1 PRISMA-P 2015 checklist

How to cite this article: Saleh MHA, Ravida A, Suarez-Lopez del Amo F, Lin G-H, Asa'ad F, Wang H-L. The effect of implantabutment junction position on crestal bone loss: A systematic review and meta-analysis. Clin Implant Dent Relat Res. 2018;20:617-633. https://doi.org/10.1111/cid.12600 